\title{
THE ESTIMATION OF THE PROPAGATION DELAY THROUGH THE TROPOSPHERE FROM MICROWAVE RADIOMETER DATA
}

\author{
J. M. Moran and B. R. Rosen \\ Harvard-Smithsonian Center for Astrophysics
}

\begin{abstract}
Uncertainty in the estimate of the microwave propagation delay through the troposphere is a principal limiting factor to the accuracy of the technique of very long baseline interferometry (VLBI). This uncertainty is due primarily to tropospheric water vapor, the total amount and vertical distribution of which is variable. Because water vapor both delays and attenuates microwave signals, the propagation delay, or wet path length, can be estimated from the microwave brightness temperature near the $22.235 \mathrm{GHz}$ transition of water vapor.
\end{abstract}

We analyzed the data from a total of 240 radiosonde launches taken simultaneously in 1974 at Chatham, Massachusetts; Albany, New York; and Portland, Maine. Estimates of brightness temperature at 19 and $22 \mathrm{GHz}$ and wet path length were made from these data. The wet path length in the zenith direction could be estimated from the surface water vapor density to an accuracy of $5 \mathrm{~cm}$ for the summer data and $2 \mathrm{~cm}$ for winter data. Using the brightness temperatures, the wet path could be estimated to an accuracy of $0.3 \mathrm{~cm}$.

Two dual-frequency radiometers constructed by the National Radio Astronomy Observatory (NRAO) were refurbished in order to test these techniques. These radiometers were capable of measuring the difference in the brightness temperature at $30^{\circ}$ elevation angle and at the zenith to an accuracy of about $1^{\circ} \mathrm{K}$. In August 1975, 45 radiosondes were launched from Haystack Observatory over an 11-day period. Brightness temperature measurements were made simultaneously at 19 and $22 \mathrm{GHz}$ with the NRAO radiometers. The rms error for the estimation of wet path length from surface meteorological parameters was $3.2 \mathrm{~cm}$, and from the radiometer brightness temperatures, $1.5 \mathrm{~cm}$. 


\section{INTRODUCTION}

The neutral atmosphere retards and attenuates propagating electromagnetic waves. The retardation limits the accuracy to which very long baseline interferometry can be used to measure radio source positions and baseline vectors between the antennas. Atmospheric water vapor can contribute up to about $40 \mathrm{~cm}$ of excess propagation path length in the zenith dircction at microwave frequencies. The exact amount cannot be predicted accurately from ground level meteorological variables since the water vapor is not well mixed in the atmosphere. However, since the index of refraction and absorption coefficient are functions of the water vapor density, the brightness temperature due to the self-emission, a weighted integral of the absorption coefficient, is related to the path length, the integral of the index of refraction. Hence, ground-based radiometric measurements can be used to estimate the excess phase path. Early evaluations of the effectiveness of this technique were made by Waters (1967) and Shaper, Staelin, and Waters (1970).

The vertical profiles of temperature and water vapor density are routinely obtained from radiosondes launched by the National Weather Service (NWS). From these data, the index of refraction can be calculated and the path delay estimated. The microwave absorption coefficient can also be calculated and the brightness temperature estimated from the equation of radiative transfer. We completed a theoretical study based on radiosondes launched at three locations in New England in order to determine how well the path delay could be estimated from: (1) surface meteorological data, (2) radiosonde data from a remote station, and (3) microwave radiometry. We also conducted an 11-day experiment during which we compared actual radiometry data from two microwave radiometers with values of brightness temperatures and path length derived from radiosonde data. Our study was focused on establishing how well various techniques work. We used the method of linear regression analysis and examined the residuals. Substantial progress has been made recently by $\mathrm{Wu}$ (1979) and Claflin, Wu, and Resch (1978) on establishing useful a priori prediction algorithms. A full report of our work is available in Moran and Penfield (1976).

\section{BACKGROUND PHYSICS}

The excess propagation path length is given by

$$
L=10^{-6} \int_{0}^{\infty} \mathrm{N}(\mathrm{h}) \mathrm{dh}
$$

where $\mathrm{N}(\mathrm{h})$ is the refractivity of the air as a function of height. The refractivity of moist air is described by the Smith-Weintraub equation (Bean and Dutton, 1966),

$$
\mathrm{N}=\frac{77.6}{\mathrm{~T}}\left(\mathrm{P}+\frac{4810 \mathrm{e}}{\mathrm{T}}\right),
$$

where 


$$
\begin{aligned}
& \mathrm{T}=\text { temperature }\left({ }^{\circ} \mathrm{K}\right) \\
& \mathrm{P}=\text { total pressure }(\mathrm{mb}) \\
& \mathrm{e}=\text { partial pressure of water vapor }(\mathrm{mb})
\end{aligned}
$$

The first term in equation (2) arises from the displacement polarizations of all the air constituents including about a 1-percent contribution from water vapor at the surface. It is called the "dry term." The second term in equation (2) is due to the dipole moment of the water vapor molecule and is called the "wet term."

The refractivity of air is essentially independent of frequency from 0 to $30 \mathrm{GHz}$. The dispersive component of the index of refraction associated with the $22.235 \mathrm{GHz}$ transition of water vapor has a refractivity which is less than 0.02 (Liebe, 1969).

Using the ideal gas law, the dry and wet components of the refractivity, $N_{D}$ and $N_{v}$, can be written as

$$
\begin{gathered}
\mathrm{N}_{\mathrm{D}}=\frac{77.6 \mathrm{P}}{\mathrm{T}}=2.70 \times 10^{4} \rho_{\mathrm{D}} \\
\mathrm{N}_{\mathrm{v}}=3.73 \times 10^{5} \frac{\mathrm{e}}{\mathrm{T}^{2}}=1720 \frac{\rho_{\mathrm{v}}}{\mathrm{T}}
\end{gathered}
$$

where $\rho_{\mathrm{D}}$ and $\rho_{\mathrm{V}}$ are the densities of dry air and water vapor in grams per cubic meter. At the surface, $N_{D}$ typically varies between 250 and 300; while in New England, $N_{V}$ varies from between about 10 and 100 .

The dry gas obeys the equation of hydrostatic equilibrium which leads immediately to the result that the excess dry path is

$$
\mathrm{L}_{\mathrm{D}}=10^{6} \int \mathrm{N}_{\mathrm{D}} \mathrm{dh}=\mathrm{AP}_{\mathrm{O}}
$$

where $P_{0}$ is the total pressure at the surface, $A=77.6 \frac{\mathrm{R}}{\mathrm{gm}}=0.2276 \mathrm{~cm} \mathrm{mb}^{-1}, \mathrm{R}$ is the universal gas constant, $\mathrm{m}$ is the molecular weight of dry air, and $\mathrm{g}$ is the surface gravity constant. Hence, the value of $L_{D}$ at sea level at the standard pressure of $1013 \mathrm{mb}$ is $231 \mathrm{~cm}$ at $45^{\circ}$ latitude. $L_{D}$ can therefore be estimated to an accuracy of less than $1 \mathrm{~cm}$ provided the pressure is measured to an accuracy of a few millibars since departures from hydrostatic equilibrium are small (Hopfield, 1971).

The partial pressure and density of water vapor are related by the ideal gas law, so that

$$
\rho_{\mathrm{v}}=\frac{217 \mathrm{e}}{\mathrm{T}} \mathrm{gm}^{-3} \text {. }
$$


The wet path length is therefore

$$
\mathrm{L}_{\mathrm{v}}=1720 \int_{0}^{\infty} \frac{\rho_{\mathrm{v}}(\mathrm{h})}{\mathrm{T}(\mathrm{h})} \mathrm{dh} .
$$

The assumption that $\rho_{\mathrm{v}}$ is an exponential function with a scale height of $2.2 \mathrm{~km}$ and $\mathrm{T}$ is constant at $290^{\circ} \mathrm{K}$ leads to the approximate formulas

$$
\mathrm{L}_{\mathrm{v}} \approx 1.3 \rho_{\mathrm{v}}
$$

and

$$
\mathrm{L}_{\mathrm{v}} \approx 1.0 \mathrm{e} \text {. }
$$

More exact analysis for prediction of path length from surface meteorological data are given by Saastamoinen (1973).

The brightness temperature at the surface of the earth, derived from the equation of radiative transfer, can be written as

$$
\mathrm{T}_{\mathrm{B}}(\nu)=\mathrm{T}_{\mathrm{c}} \mathrm{e}^{-\tau \nu}+\int_{0}^{\infty} \mathrm{T}(\ell) \alpha(\nu, \ell) \mathrm{e}^{-\tau^{\prime}(\nu, \ell)} \mathrm{d} \ell,
$$

where

$$
\tau_{\nu}^{\prime}=\int_{0}^{\ell} \alpha(\nu, \ell) \mathrm{d} \ell
$$

and

$$
\tau_{\nu}=\int_{0}^{\infty} \alpha(\nu, \ell) \mathrm{d} \ell
$$

and where $\ell$ is the distance along the ray path from the observer, $\alpha(\nu, \ell)$ is the absorption coefficient, $T_{c}$ is the brightness temperature of any extraterrestial radiation source, $\tau_{\nu}$ is the total atmospheric opacity along the ray path, and $\tau_{\nu}$ is the opacity between the point of emission and the observer.

The principal contribution to the microwave absorption coefficient are water vapor and oxygen. The opacity due to oxygen at $22 \mathrm{GHz}$ is about 0.013 nepers; therefore, the brightness temperature contribution is only about $4^{\circ} \mathrm{K}$. This contribution changes very little with time. The absorption coefficient for oxygen, taken from Meeks and Lilley (1960) has been included in our calculations. The absorption coefficient due to the water vapor for the $6_{16}-5_{23}$ transition having a rest frequency, $\nu_{0}$, of $22.23508 \mathrm{GHz}$ is given by Staelin (1966) as 


$$
\begin{aligned}
\alpha(\nu, \ell)= & 3.24 \times 10^{-4} \mathrm{e}^{-664 / \mathrm{T}} \frac{\nu^{2} \mathrm{P} \rho_{\mathrm{v}}}{\mathrm{T}^{3.125}}\left(1+0.0147 \frac{\rho_{\nu} \mathrm{T}}{\mathrm{P}}\right) \\
\cdot & {\left[\frac{1}{\left(\nu-\nu_{\mathrm{o}}\right)^{2}+\Delta \nu^{2}}+\frac{1}{\left(\nu+\nu_{\mathrm{o}}\right)^{2}+\Delta \nu^{2}}\right] } \\
& +2.55 \times 10^{-8} \rho_{\mathrm{v}} \nu^{2} \frac{\Delta \nu}{\mathrm{T}^{3 / 2}} \mathrm{~cm}^{-1}
\end{aligned}
$$

where

$$
\Delta \nu=2.58 \times 10^{-3}\left(1+0.0147 \frac{\rho_{\mathrm{v}} \mathrm{T}}{\mathrm{P}}\right) \frac{\mathrm{P}}{(\mathrm{T} / 318)^{0.625}}
$$

and $\nu$ is the frequency in $\mathrm{GHz}$.

The brightness temperature at center line, for the case where $\tau_{\nu} \ll 1$, is therefore

$$
\mathrm{T}_{\mathrm{B}} \propto \int_{0}^{\infty} \frac{\rho_{\mathrm{V}}}{\mathrm{PT} \cdot 875} \mathrm{e}^{-644 / \mathrm{T}} \mathrm{dh}
$$

whereas

$$
\mathrm{L}_{\mathrm{v}} \propto \int_{0}^{\infty} \frac{\rho_{\mathrm{v}}}{\mathrm{T}} \mathrm{dh} .
$$

To a first approximation, we find that $\mathrm{T}_{\mathrm{B}}\left(\mathrm{H}_{2} \mathrm{O}, \nu=22 \mathrm{GHz}\right)\left({ }^{\circ} \mathrm{K}\right) \sim 2.1 \mathrm{~L}_{\mathrm{v}}(\mathrm{cm})$. P decreases by 10 percent per kilometer and $\mathrm{T}$ by 2 percent per kilometer so that a given amount of water vapor contributes more heavily at higher altitudes to the brightness temperature than to the wet path length although saturation tends to reduce the discrepancy. Frequencies can be chosen to maximize the correlation between path length and brightness temperature (Wu, 1979).

\section{RADIOSONDE STUDIES}

Radiosondes are launched routinely at 11 and 23 hours UT from Portland, Maine; Chatham, Massachusetts; and Albany, New York by the National Weather Service. We obtained data for 50 occasions during which simultaneous launches were made at the three stations in July and August 1974 and for 30 occasions in January and February 1974. The data of the significant reporting points were used in our analysis. The geopotential height was calculated from the pressure and temperature (Hess, 1959), and the water vapor density was calculated from the dew point depression and temperature. The absorption coefficient was calculated as a function of height from $\rho_{\mathrm{v}}, \mathrm{P}$, and $\mathrm{T}$. 
The wet path and the brightness temperatures were calculated from equations (7), (10), (13), and (14) using the trapezoidal rule for integration. The mean and $r \mathrm{rs}$ of $L_{v}$ were $17 \pm 7 \mathrm{~cm}$ and $5 \pm 2 \mathrm{~cm}$ for summer and winter.

The calculated values of wet path length and brightness temperature were compared in various ways with a simple least-mean-square analysis program. Some of the results are shown in table 1 . To see how well the wet path length could be predicted from the surface density of water vapor, $\rho_{0}$, the data were fit to the equation

$$
\mathrm{L}_{\mathrm{v}}=\mathrm{A}_{1} \rho_{\mathrm{o}}+\mathrm{A}_{2} \text {. }
$$

The rms deviations in path length were typically $5 \mathrm{~cm}$ for the summer data and $2 \mathrm{~cm}$ for the winter data. Hence, surface data only offers a slight improvement in the estimate of $\mathrm{L}_{\mathrm{V}}$ compared to predictions from the climatic mean.

Tablc 1

rms Error in Predicting Wet Path Length from Various Parameters

\begin{tabular}{|l|c|c|}
\hline \multicolumn{1}{|c|}{ Predictor } & $\begin{array}{c}\text { summer } \\
\sigma \\
(\mathrm{cm})\end{array}$ & $\begin{array}{c}\text { winter } \\
\sigma \\
(\mathrm{cm})\end{array}$ \\
\hline Seasonal mean (1) & 6.9 & 3.1 \\
Seasonal mean (2) & 4.4 & 2.2 \\
Surface meteorology (1) & 5.1 & 2.1 \\
Surface meteorology (2) & 3.7 & 2.0 \\
Surface meteorology (3) & 3.9 & 2.4 \\
Remote station radiosonde (1) & 5.0 & 1.5 \\
$\mathrm{~T}_{22}$ and $\mathrm{T}_{19}(1)$ & 0.3 & 0.2 \\
$\mathrm{~T}_{22}(1)$ & 0.4 & 0.4 \\
\hline
\end{tabular}

NOTES: (1) Portland-Chatham-Albany data from this study.

(2) Huntington, W. Va. data from Schaper et al. (1970).

(3) Nlbany, N.Y. data from Crane (1976). 
The hypothesis that the wet path at one station might be useful in predicting the wet path at another was examined. Wet path data from the station $i$ was fit to the wet path data from the station $\mathrm{j}$ with the equation

$$
L_{v_{i}}=A_{1} L_{v_{j}}+A_{2} \quad i \neq j .
$$

The mean of the rms deviations were $5 \mathrm{~cm}$ for the summer data and $1.5 \mathrm{~cm}$ for the winter. The wet path length is therefore fairly well decorrelated over a distance of $200 \mathrm{~km}$. Hence, the remote profiles are no better than local measurements of surface meteorology for the prediction of the wet path length.

The correlation between brightness temperatures at 22 and $19 \mathrm{GHz}, \mathrm{T}_{22}$ and $\mathrm{T}_{19}$, and wet path length were calculated by fitting the data to the equations

$$
\mathrm{L}_{\mathrm{v}}=\mathrm{A}_{1} \mathrm{~T}_{22}
$$

and

$$
L_{v}=A_{1} T_{22}+A_{2} T_{19}+A_{3} .
$$

The rms deviations for the two-temperature fit for the summer and winter data were $0.3 \mathrm{~cm}$ and 0.2 $\mathrm{cm}$, showing that wet path length and brightness temperature are well correlated.

\section{RADIOMETERS}

The two radiometers in our study were built at the National Radio Astronomy Observatory in 1968. Their characteristics are summarized in table 2 . In order to measure the antenna temperatures at two frequencies, 19 and $22 \mathrm{GHz}$, each radiometer was configured as a dual-Dicke-switched radiometer which switched between the antenna and an ambient load at $50 \mathrm{~Hz}$ and between frequencies at $2 \mathrm{~Hz}$. Although the radiometers were very stable, drifting less than $0.3^{\circ} \mathrm{K}(\mathrm{rms})$ over many hours, absolute calibration was difficult. The accuracy of the noise tube calibration was measured to be about 1.5 percent. Hence, the absolute calibration with respect to the $295^{\circ} \mathrm{K}$ load was about $3.5^{\circ} \mathrm{K}$. To avoid the need for absolute measurements, observations were made at different elevation angles. The observable used was the brightness temperature at $30^{\circ}$ elevation angle minus that at the zenith. For a temperature difference of about $30^{\circ} \mathrm{K}$, the calibration error was about $0.5^{\circ} \mathrm{K}$. The synchronous detectors suffered a peculiar problem that increased the rms accuracy of the temperature measurements by $1.5^{\circ} \mathrm{K}$. This was, therefore, the dominant contribution to the total measurement error of about $1.6^{\circ} \mathrm{K}$.

\section{THE AUGUST 1975 RADIOSONDE EXPERIMENT}

In August 1975, an experiment was performed at the Haystack Observatory in Westford, Massachusetts, to determine the accuracy of using data from the NRAO radiometers to predict the wet path length. A direct comparison of the radiosonde and radiometer data was made at that time. 
Table 2

Radiometer Characteristics

\begin{tabular}{|l|l|}
\hline Source & NRAO (constructed 1968) \\
Antenna & $92 \mathrm{~cm}$ paraboloid \\
Beamwidth (FWHM) & 61 arc minutes \\
Peak sidelobe & $-22 \mathrm{db}$ \\
Pointing accuracy & $\pm 0.5^{\circ}$ (potientometer encoders) \\
Receiver & Superhetrodyne, mixer first stage \\
Receiver Temperature & $1500^{\circ} \mathrm{K}$ \\
Bandwidth & $300 \mathrm{MHz}$ \\
$\Delta \mathrm{T}$ (rms) (4 sec) & $0.1^{\circ} \mathrm{K}$ \\
$\Delta \mathrm{T}$ (rms) (5 hours) & $0.2^{\circ} \mathrm{K}$ \\
Noise tube accuracy & $1.5 \%$ \\
Reference load temperature & $294^{\circ} \mathrm{K}$ \\
Tuning range & $18-24 \mathrm{GHz}$ \\
Dicke switching & $4^{\circ} \mathrm{K}$ \\
Observation frequencies & $0.9^{\circ} \mathrm{K}$ \\
Absolute calibration & $19.0,22.2 \mathrm{GHz}$ \\
\hline
\end{tabular}


The radiosondes were launched by NWS at the NASA Wallops Island Facility. The radiosondes contained carbon elements for sensing relative humidity (Brousaides and Morrissey, 1974). Forty-five radiosondes were launched over an 11-day period from August 14 to 25, 1975. The basic data were a series of measurements of pressure, temperature, and relative humidity from the radiosondes and the tracking angles of the telemetry antenna. NWS supplied us with reduced profile data consisting of pressure, temperature, water vapor density, wind speed and direction, and other quantities derived from them, at intervals of 100 feet (after interpolation) from the surface to an altitude of 30,000 feet. Typically, the radiosondes drifted eastward from Haystack and were at an elevation angle of $30^{\circ}$ at $1 \mathrm{~km}$ altitude. The total pressure, partial pressure of water vapor, and temperature at the surface are plotted in figure 1 and show that during the period of the experiment, two weak frontal disturbances passed. The mean profile of water vapor density is shown in figure 2 . The profile has, approximately, an exponential dependence with a scale height of $2.2 \mathrm{~km}$, although the high altitude part decreases more slowly than an exponential. Individual profiles deviated greatly from exponential dependence.
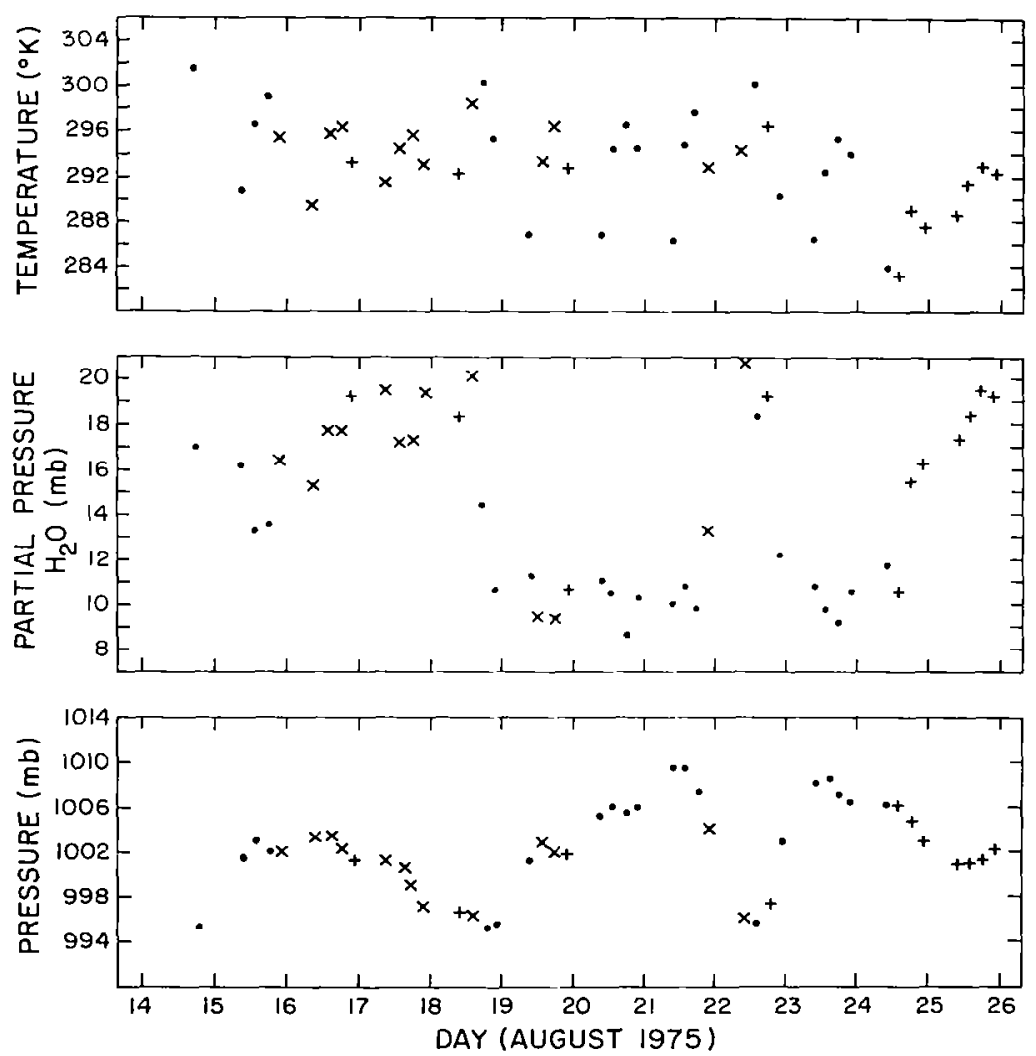

Figure 1. The temperature, partial pressure of water vapor, and total pressure measured at the surface before each radiosonde launch in August 1975. The symbols denote different cloud cover conditions: $(\cdot) \leq 2 / 10$ cover or thin cirrus (21 launches); $(x)>2 / 10$ and $\leq 6 / 10$ cover (13 launches); $(+)>6 / 10$ cover ( 11 launches). 


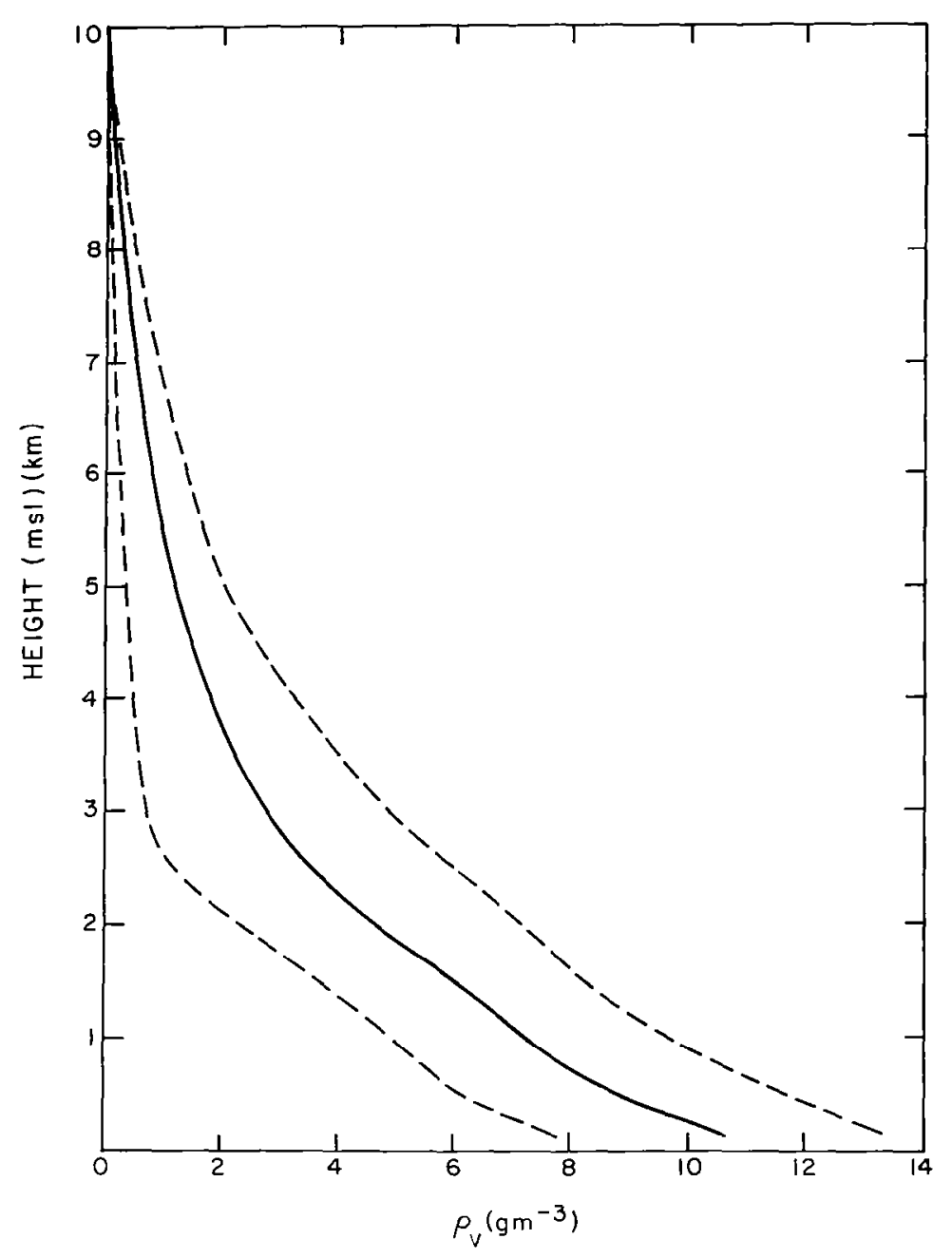

Figure 2. The mean profile of the water vapor from the data of 45 radiosonde launches at Haystack Observatory in August 1975. The dotted lines denote plus and minus one standard deviation.

During each balloon flight, which lasted about 30 minutes, six tipping scans were made at different azimuthal angles. The values of brightness temperature, $\mathrm{T}\left(30^{\circ}\right)-\mathrm{T}$ (zenith), were averaged for each balloon flight. The set of 45 brightness temperatures for each frequency and radiometer were compared to those calculated from the radiosonde data (as described in section II) in order to calibrate the radiometers. The temperature data sets (i.e., temperatures at two frequencies from the two radiometers and the radiosonde estimates) were fit to the equation

$$
T_{i}=A_{1} T_{j}+A_{2} \quad i \neq j .
$$

The values of $\mathrm{A}_{2}$ were typically less than $1^{\circ} \mathrm{K}$. The rms deviation was $1.2^{\circ} \mathrm{K}$ in the comparison of data from radiometers 1 and 2 , implying the radiometer measurements were accurate to $0.9^{\circ} \mathrm{K}$ 
(i.e., $1.2 \% \sqrt{2}$ ). Most of this error was caused by the problem with synchronous detector. The expected radiometer error was $1.6 / \sqrt{6}$ or $0.7^{\circ} \mathrm{K}$. The rms deviation in the fit of radiometer temperatures to radiosonde predicted temperatures was typically $2.5^{\circ} \mathrm{K}$. This suggests that most of the experimental error was in the radiosonde data, or due to the effects of clouds.

Extensive correlation analysis was performed between radiometer temperatures and the wet path and theoretical temperatures estimated from radiosonde data. A plot of the wet path versus brightness temperature at $22 \mathrm{GHz}$ is shown in figure 3. The path length predicted by radiometer 1 from equation (20) is plotted versus the path length estimated from the radiosonde data in figure 4.

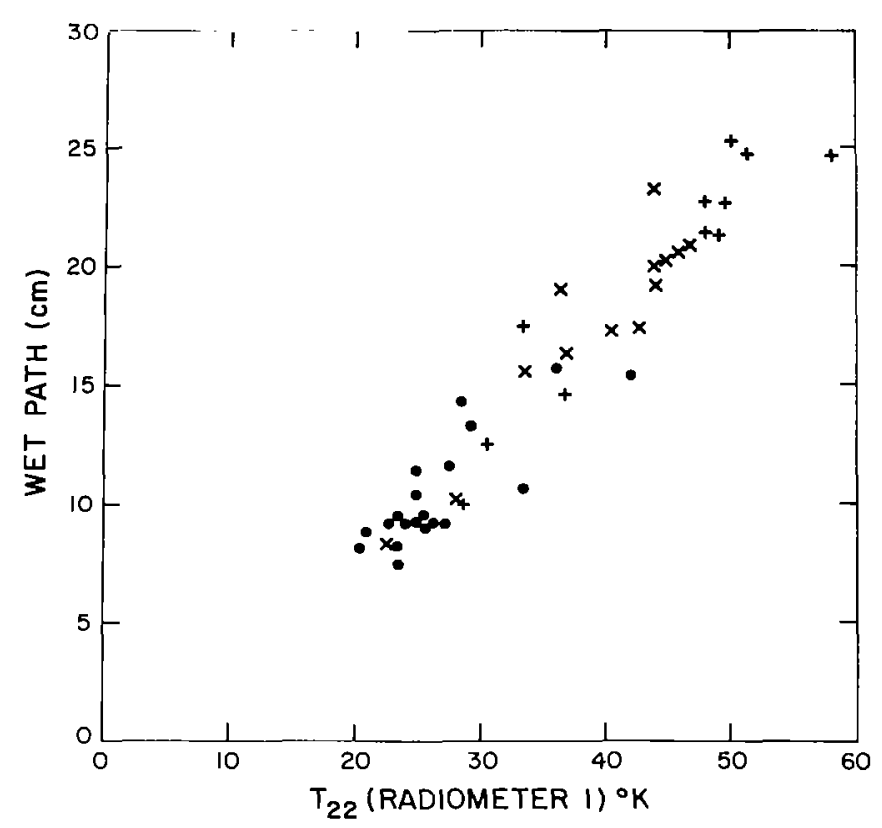

Figure 3. The wet path lengths for the vertical direction calculated from radiosonde profiles versus the brightness temperature ( $\mathrm{T}\left(30^{\circ}\right)-\mathrm{T}$ (zenith)) at $22.2 \mathrm{GHz}$ measured by one of the NRAO radiometers. The symbols, denoting different cloud conditions, are defined in the caption to figure 1. The non-zero intercept is due largely to oxygen emission.

\section{CONCLUSIONS}

The residuals from various regression analyses for the August 1975 experiment are listed in table 3 . We reached the following conclusions:

1. The mean value of the path lengths estimated from radiosonde data for the 45 launches was $14.8 \mathrm{~cm}$ with an rms deviation of $5.6 \mathrm{~cm}$. For the 21 radiosondes launched in clear or nearly clear skies, the mean was $10.3 \pm 2.5 \mathrm{~cm}$. 


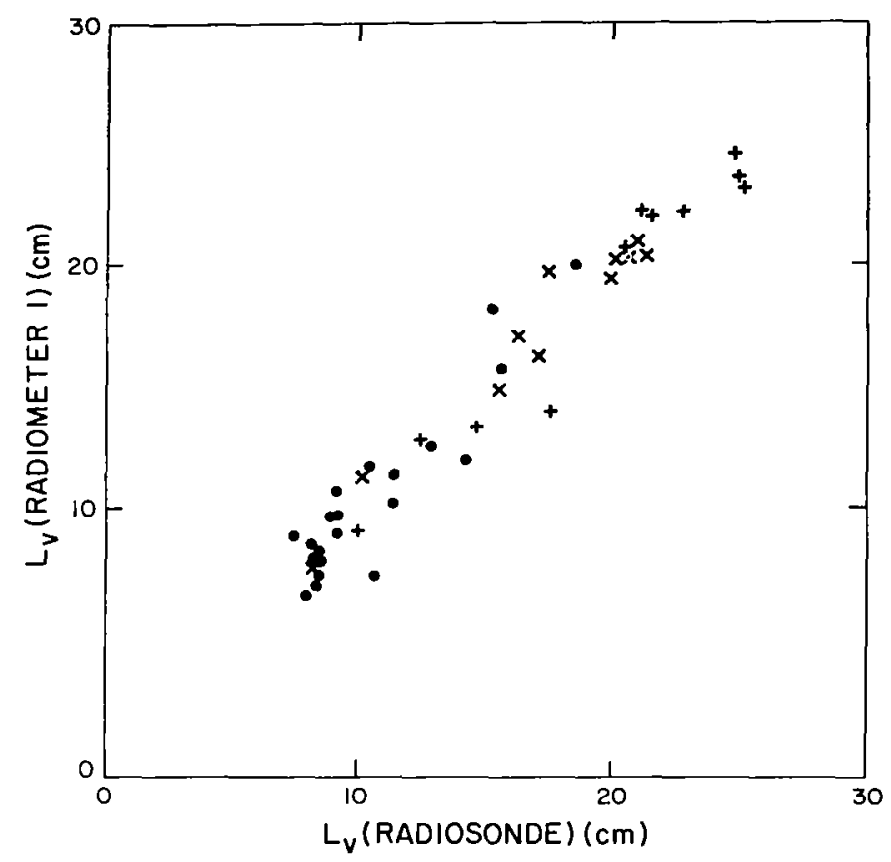

Figure 4. The wet path length, estimated from the formula $L_{v}=T_{1} T_{22}+A_{2} T_{19}+A_{3}$ with temperatures from radiometer 1 versus the wet path lengths derived from radiosonde data. The coefficients $A_{1}, A_{2}$, and $A_{3}$ were derived by fitting the brightness temperatures from the radiometers to the wet path length estimated from the radiosonde data.

2. Prediction of the wet path length from the surface partial pressure of $\mathrm{H}_{2} \mathrm{O}$ had an $\mathrm{rms}$ deviation of $3.2 \mathrm{~cm}$, an improvement over the rms deviation about the mean.

3. Prediction of the wet path length at Haystack from those estimated for Portland, Albany, and Chatham gave no better results than prediction from local surface meteorology.

4. The rms deviation in wet path length estimated from radiometer data was $1.5 \mathrm{~cm}$.

5. The rms deviation in path length predicted from brightness temperatures computed from radiosonde data was only $0.4 \mathrm{~cm}$. This may represent the ultimate accuracy of the technique without adding higher-order regression coefficients or correcting for the effects saturation caused by large microwave opacity.

The results from this experiment were consistent with the results from our previous analysis of radiosondes launched at Albany, Portland, and Chatham. The residuals for the winter data were, of course, much smaller. 
Table 3

Results of Regression Analysis on August 1975 Data

\begin{tabular}{|l|c|c|c|}
\hline \multicolumn{2}{|c|}{ RMS Residuals in Wet Path Length } \\
\hline \multicolumn{1}{|c|}{ Predictor } & \multicolumn{1}{|c|}{ Fit(3) } & All data(1) & Best Weather data (2) \\
\hline Mean & $\mathrm{L}_{\mathrm{v}}=\mathrm{A}_{1} \mathrm{e}+\mathrm{A}_{2}$ & $5.6 \mathrm{~cm}$ & $2.5 \mathrm{~cm}$ \\
Surface partial pressure & $\mathrm{L}_{\mathrm{v}}=\mathrm{A}_{1} \mathrm{~L}_{\mathrm{v}_{1}}+\mathrm{A}_{2} \mathrm{~L}_{\mathrm{v}_{2}}+\mathrm{A}_{3} \mathrm{~L}_{\mathrm{v}_{3}}$ & 3.0 & 1.5 \\
$\begin{array}{l}\text { Path length from radio- } \\
\text { sondes at Portland, } \\
\begin{array}{l}\text { Albany, Chatham } \\
\begin{array}{l}\text { Brightness temper- } \\
\text { atures from NRAO } \\
\text { radiometers }\end{array}\end{array} \\
\begin{array}{l}\text { Brightness temper- } \\
\text { atures estimated from } \\
\text { radiosonde data }\end{array}\end{array} \mathrm{L}_{\mathrm{v}}=\mathrm{A}_{1} \mathrm{~T}_{22}+\mathrm{A}_{2} \mathrm{~T}_{19}+\mathrm{A}_{3}$ & 1.5 & \\
\hline
\end{tabular}

NOTES: (1) 45 data points.

(2) 22 data points for which cloud cover was $\leq 0.2$.

(3) $\mathrm{L}_{\mathrm{v}}$ estimated from radiosonde data.

The stability of the regression coefficients derived presents a problem requiring some study. Wu (1979) has shown that coefficients can be found which are insensitive to climatic conditions if correct pairs of frequencies are chosen. Wu requires that the coefficients satisfy the relation $\left(A_{1} / A_{2}\right)=$ $-\left(\nu_{2} / \nu_{1}\right)^{2}$ so that the brightness temperature of clouds, which is proportional to $\nu^{2}$, does not effect the path length estimate. With this constraint, 19 and $22 \mathrm{GHz}$ are not a good frequency pair. A good way to include the radiometer data in the analysis of VLBI data may be to add the observed brightness temperatures to the data base of measured interferometer observables and estimate the regression coefficients for each site in the general data analysis. In this way the stability of the coefficients under different climatic conditions is less important.

This work was supported under NASA contract NAS5-20975. We thank Hays Penfield and Joe Hayes for construction and operating support, and I. I. Shapiro, C. C. Counselman, and C. A. Knight for helpful discussions. 


\section{REFERENCES}

Bean, B. R., and Dutton, E. J. 1966, Radio Meteorology, U.S. Gov’t. Printing Office.

Brousaides, F. J., and Morrisey, J. F. 1974, Residual Temperature-Induced Humidity Errors in the National Weather Service Radiosonde. AFCRL Report TR-74-0111.

Claflin, E. S., Wu, S. C., Resch, G. M. 1978, DSN Progress Report 42-48, 22.

Crane, R. K. 1976, Refraction Effects in the Neutral Atmosphere in Methods of Experimental Physics ed. by M. L. Meeks, Academic Press, New York, Vol. 12B, p.. 186.

Hess, S. L. 1959, Introduction to Theoretical Meteorology, Holt Co., New York

Hopfield, H. S. 1971, Radio Science 6, 357.

Liebe, H. 1969, IEEE Trans. Ant. Propag. AP-17, 621.

Meeks, M. L., and Lilley, A. E. 1963, J. Geophys. Res., 68, 1683.

Moran, J. M., and Penfield, H. 1976, NASA Contract Report NAS5-20975.

Saastamoinen, J. 1972, AGU Geophysical Monograph 15, The Use of Artificial Satellites for Geodesy (ed: S. Henriksen, A. Mancini, B. Chovitz) p. 247.

Shaper, L. W., Staelin, D. H., and Waters, J. W. 1970, P.I.E.E.E., 58, 272.

Staelin, D. H. 1966, J. Geophys. Res., 71, 2875.

Waters, J. W. 1967, NRAO VLA Scientific Memorandum No. 8.

Waters, J. W. 1976, Absorption and Emission by Atmospheric Gases in Methods of Experimental Physics, ed. by M. L. Meeks, Academic Press, New York, Vol. 12B, p. 142.

Wu, S. C. 1979, I.E.E.E. Trans. Ant. and Prop. AP-27, 233. 